\title{
Autonomous Learning and College English Teaching
}

\author{
Xiaoyan Wang ${ }^{1}$ \\ ${ }^{1}$ Jiangxi Institute of Economic Administrators, Nan Chang, Jiang Xi, 330038 \\ 346591653@163.com
}

KEYWORDS: Autonomous Learning; College English; Student Cultivation

\begin{abstract}
In the current College English teaching mode, the primary object relation has not been a clear understanding of teaching and learning, teachers and students in the teaching process positioning are fuzzy, subjective initiative play hard to get; teaching activity-dependent class, teaching content fixed uniform materials, such teaching about the textbooks, students rely on teachers, not just a single model and it is difficult to reflect the personality of teachers and students. The lack of participation and student exchange opportunities are not easy to achieve individualized. English teaching requires not only multimedia stimulus - response, need guidance, consulting and communication activities. Therefore, the authors believe that the main object relations English teaching, teachers and students in English teaching roles and functions as well as inside and outside class teaching mode, are required to study.
\end{abstract}

\section{Introduction}

Teachers and students can be used as the main body, who is the subject, depends on the specific role of teachers and students in the teaching activities may be. Dual Subject of view, from the understanding of the main object, the teachers and students have as subject and object conditions, but teachers and students in the teaching process of influence and be influenced, reflect the relationship is not being reflected in one way, but two-way multi-polar. Investigation of teachers and students in the teaching activities, each only two relatively independent subject, is the object of knowledge of each other object, and its presentation is often interacting with each other, so there is a mutual constraints between teachers as subject or object with students conversion of the dialectical relationship, and both have their own characteristics in time and as a host. Teachers are the main characteristics of the main social, practicality and initiative; the main characteristics of the student body are unique, autonomy and creativity. Uniqueness and autonomy requirements due to material selection and individualized teaching, teaching democracy requires creativity and learning potential mining. Teachers, students inter-subjectivity, namely teaching body double is more representative view: education and the educated into two teaching and learning activities, both as the main educational activities. It believes that education is the subject of teaching by activity and it is the driving force behind educational activities, leadership and promotes the development of the entire educational process and to achieve the aims of education. Educators are the main source of education on educational activities, is director of student learning activities, living in the dominant position of the entire educational activities, it has a decisive influence on the direction of development and progress. Educated is the object of teaching activities, the object of education is affected, but in school activities is the development and understanding of the subject, but also the discoverer. Thus, in education, the status of education and the educated will have a certain degree of 
relativity. Although the two different educational activities undertaken in the task, but relative to other fundamental factors in terms of educational activities, and are in a dominant position; it is the relationship between the two, and object-oriented mutual.

\section{The Theory of Subject and Object on English Teaching}

Humanism (humanism) that the world is the concept of people's basic category, requiring departure from the concept of man, society and nature to explore the concept of systems thinking, which is representative of the early Feuerbach and Chernyshevsky et al. So Broadly speaking, this is about people human nature/essence of the doctrine. From the narrow sense, it is a philosophical school of the 1930s in western Europe. Humanistic psychology emphasizes the talent of humanity, requires departure from the subjective consciousness, people's motivation to solve the whole personality, which illustrate the nature and characteristics of the human inner modality, potential intelligence, purpose, hobbies, interests and other human experience. It is opposed to unconscious motives environmentalism behaviorism, psychoanalysis against determinism against any split or whole reduction. Humanistic psychology with particular emphasis on freedom of initiative and selective human consciousness has, that the people according to their intentions, to determine their value. Maslow and Rogers is well-known representatives of Humanistic Psychology. Rogers also published many teaching theory point of view, one of the student center, said more references in English teaching. Establish autonomous English learning environment takes advantage of some of the points of humanistic psychology. Student Center On Rogers was one of his three teaching point of view, the other two is the purpose of teaching theory and teaching methods theory. About the purpose of teaching, Rogers considered adequate to promote the development of student's personality. Connotation "full development" refers to the full development and emotional intelligence on. "Full development" of the performance is to be able to adapt to change and learn to know why. Because people want to adapt to change, so any static knowledge is unreliable, and only seek dynamic process of knowledge, the know why to learn, to adapt to change in order to achieve the purpose. Based on this concept of teaching purposes, Rogers believes that education is the key means of achieving the attitude of the teachers and students. From the student's attitude, he said, mainly to ensure that self-realization and inner driving force caused; from the teachers' attitude, is to relieve stress of students, so that they have a sense of security in the study. For this reason teachers must believe that students can develop their potential, sincere treatment of students, respect for students' personal experience and attention to their feelings and opinions, and in-depth understanding of the students, a lot for their sake. Clearly, teachers' attitudes are to ensure that students' self-realization services is nice.

\section{Construction of Autonomous English Learning Environment}

English learning environment is to rely on English teaching actual circumstances. This is first of all to determine the environmental field. Autonomous English learning environment identified environmental education field than the wider identified some, but less than the ecological environment and environmental psychology identified so wide. It is according to the definition of system theory, the existence of regional contact occurs directly with the teaching and the role of all external conditions considered environmental field; then look at environmental factors. In a nutshell, all the constraints, the impact of English learning activities and effects of external conditions, whether dynamic or static, environmental factors are independent of the identified learning English. Analysis to say that education policy, special equipment policy, teaching plans, curricula, textbooks 
and supplementary materials and teaching aids, teaching non-English subjects, school facilities, teaching English and specific teaching methods and the like are present in the area of the school environment factor; economic development of the school community, the perception of the English and the need for it, and so is present in the community school where environmental factors; cultural taste of family members, occupation, wealth and experience as well as English level, learning experiences and learning styles, etc., is present in the environment factors students themselves. In addition, the spread of the role played by teachers that can also be counted as one of the environmental factors.

All learning activities are directly or indirectly, or strong or weak to influence by the mother tongue, which makes impossible to exclude the teaching of English mother tongue. So students learn a second language in English, not starting from scratch, may begin up some simple body language, some language-based system. Start learning in two forms: one form, no matter what is the student's mother tongue, language learning the same exhibit essentially the same development program, the same operation that is the starting point for students of different mother tongue; the other is only up the same students in learning the same non-native languages, only render the same word order, the same operation that is the same as speaking students learning starting point. Comprehensive two assumptions, it can be said, the proximity of the target language with native speakers of English decides the starting point for the level of learning. European and American students learning English as a mother tongue, French and their native language or belong to the same language family, or belonging to the same Indo-European, the starting point for them to learn high; our students' native language Sino-Tibetan language family, Indo-European and extremely alienated our students learning English and other languages low starting point. This shows that the teaching environment restricts the teaching object fundamentally. Further, since the conditions are not met without teaching you turn off the English class, or because the community culture, the economy is relatively backward and teaching materials as well as low demand for easy handling, environmental effects are considered to object.

Education has to influence the process of teaching and subject to change destination. Influence the process for teachers is reflected in the main, students object. Specifically, the main role played by teachers is to provide the environment to create an atmosphere, to provide material, to help responsible for developing curricula and teaching programs, to determine the status of this course. After that, teachers develop a curriculum to determine the learning materials to construct the learning environment, the next task is to make the teaching process of the object changes, is student-based learning activities, students can organize their study time to master their own learning progress, according to the teachers required to complete the learning task within the stipulated time, give full play to students' initiative, initiative. At this stage, the teacher walked from behind the stage, students from the curricular to extracurricular. Teachers and students of the role and status have changed and the role of teachers by the body into the object, and the role of students from the object into the body. Therefore, the ideal learning environment should give full play the main role of double teachers and students, teachers teaching enthusiasm and creativity and students' enthusiasm and creativity into full play, so that teaching and learning optimized. As traditional graduate English teaching involved only teaching media materials, audio-visual materials until recently, have not provided the means in accordance with their wishes Reconstruction of teaching material for teachers, it is difficult for the students to choose their own content and learning therefore, the learning environment and is not listed as environmental factors affect learning, with the development of modern multimedia technology, media for human language learning diversified, you can make English teaching and learning environment in line with the law of teaching learning, 
greatly improved English learning efficiency, it has become one of the factors that influence learning.

The relationship between autonomy and independent learners learning environment provides a new role for teachers. So that teachers and students over the years to break the tradition of 'teaching' and 'learning' role relationship. Autonomous learning requires both students and teachers have to change roles, or even swap roles. Students will learn to think, to gradually take responsibility for their own learning, make rational decisions, to get rid of dependence on teachers, teachers gradually abandon learning and learning process responsible ideas. Teacher has a broader role than in the past and multiple responsibilities, 'teach' is just a small piece of functionality, he should not only participate in the management, operation and development of language courses, production of materials, but also should be learners consultant, sources of information, and learners should also be evaluated.

\section{Conclusion}

Improve and enhance the overall quality of modern education goals more people tend to self-learning ability, the kind of focus only on teaching concepts and methods to instill knowledge can not meet the needs of the times, especially in the education of the world and the concept of generations and future-oriented approach under the guidance of how to train high-quality talent with independent learning ability has become the focus of attention of every educator. At the same time, cultivate self-learning ability is the dynamic process of a gradual, not overnight. But we firmly believe that if we consciously in foreign language teaching to train the learners independent learning ability, we are from completely customize the ultimate goal will be getting closer.

\section{REFERENCE:}

[1] Holee, H Autonomy and Foreign Language Learning Oxford: Pergamon Press, 1981: 34.

[2] John. M. Self-Assessment in Proceedings of Self-Directed Learning and Self-Accessin Australia: From Practice to Theory, Conference held in 1984 by Coimeil of Adult Education, Melbourne, Australia.1985: 45-46.

[3] Xiao Fei. learning autonomy and how to foster language learning foreign language .2002,6 Autonomy: 24-27.

[4] Dai Zhongming. College English Teaching in Quality Education in Western circles, 2000,4: 30-36. 